\title{
El mercado en la antigua Roma y la economía agropecuaria en tiempos de crisis
}

\author{
Juan José Ferrer Maestro \\ Universitat Jaume I, Castellón \\ jferrer@uji.es
}

\section{RESUMEN}

Este trabajo presenta una síntesis del concepto de mercado e indaga en los rasgos que caracterizan la economía del Imperio romano. En él se afirma la consistencia y protagonismo de la producción agrícola en los siglos de la antigüedad tardía y se evidencia el escaso espíritu mercantil de los ricos propietarios de tierras.

Palabras clave: Economía romana. Mercado romano. Comercio romano. Crisis económica del Imperio romano. Teoría económica.

\section{The market in Ancient Rome and farming economy in times of crisis}

\begin{abstract}
This paper presents an overview of the market concept and investigates the features that characterize the economy of the Roman Empire. The agricultural production leadership and importance in the Late Antiquity is asserted, unveiling the scarce mercantile spirit among the wealthy landowners.
\end{abstract}

Key words: Ancient Rome economy. Roman market. Roman trade. Roman Empire economic crisis. Economic theory.

Sumario: 1 . Antigüedad y mercado. 2. El caso romano, ¿economía redistributiva o economía organizada? 3. La economía en crisis. 4. Conclusiones. 


\section{ANTIGÜEDAD Y MERCADO}

Es frecuente que el estudio de la economía de la Antigüedad se vea dificultado por la escasez o ausencia de datos contables contemporáneos a cada periodo histórico, por el complejo análisis y tratamiento de los mismos, o por el magro interés de las fuentes documentales en proporcionar informaciones secuenciales sobre periodos concretos. Consecuentemente, es preciso ponderar el valor de tales fuentes en cada uno de los casos en los que son requeridas como necesarias e imprescindibles para formular conclusiones. Los elementos cuantitativos con los que se pueden extraer algunos datos económicos se obtienen de aquellos documentos que los presentan como magnitudes de interés particular o institucional, en algunos casos, mientras en otros son esgrimidas como elementos propagandísticos. Entre los diferentes ejemplos que podemos utilizar se encuentran las cartas de negocios de tiempos de Hammurabi procedentes de los karu de Nínive, Sippar, Ur, Larsa o Babilonia; ${ }^{1}$ las más de 22.000 tablillas capadocias que componen los archivos de los mercaderes asirios que trajinaron con la riqueza metalífera de Anatolia en el siglo XIX a.C., halladas principalmente en Kültepe ${ }^{2}$ las cifras dadas por Tito Livio correspondientes a los botines conseguidos por los generales romanos en sus guerras de expansión; $;^{3} \mathrm{o}$ la abundante información en papiros que proporciona el Egipto romano, una información de difícil contextualización y racionalización en el estudio de costes y precios, sobre todo fuera del país del Nilo. ${ }^{4}$ En todas estas aportaciones no existe referencia alguna a la tipificación que un economista de la actualidad no dudaría en formular sobre los distintos sistemas económicos que las han generado. Por eso resulta plausible comprobar la existencia de una tenaz controversia que hace casi un siglo y medio animó el estudio y consideración de la economía de la Antigüedad, originada en el análisis del oikos, una formulación teórica elaborada por Karl Rodbertus a mediados del siglo XIX, para ser utilizada como única base de imposición fiscal en la Antigüedad clásica. ${ }^{5}$

Esencialmente se trata de conocer el proceso de transición de una economía natural (Naturalwirtschaft) a una economía monetaria (Geldwirtschaft), que no fue sólo una cuestión técnica resultante de la sustitución del trueque por la compra con metales. Dado que el uso de la moneda surgía en un entramado social completamente diferente del imperante en una economía de intercambios en especie, había que prestar atención a los cambios sociales y no a la cuestión formal de la aplicación del dinero. De ahí la importancia del oikos, (elemento único y representativo de todas las posesiones y rentas del hacendado grecorromano) el cual se gravaba con un sólo impuesto: el tributum, en contraposición al complejo sistema fiscal de las sociedades modernas (las de Rodbertus y las nuestras), con una economía expansiva cuyas cargas tributarias se aplican distinguiendo entre ingresos por rentas y patrimonio personal.

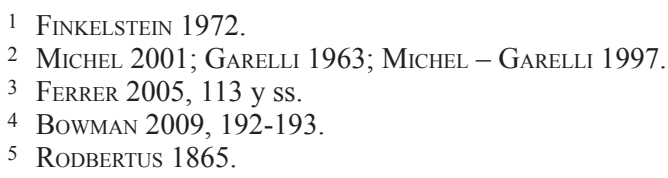

5 RodBertus 1865. 
El elemento básico que suscitó posteriormente la discusión fue la afirmación de Rodbertus de que en esta economía del oikos no intervienen la compra y la venta. Como el dividendo nacional no cambia de manos, nunca se divide en las diversas categorías de ingresos, como en los tiempos modernos. Se trata de una economía en especie que no necesitaba ningún dinero para hacer que el dividendo nacional pasara de una fase de producción a la otra, pues no intervenía en el proceso ningún cambio de propiedad. ${ }^{6}$ Es conveniente aclarar que en una economía moderna en expansión las diversas etapas de la producción están ligadas entre sí a través del proceso de compra y venta, creando así diversos grados de participación en el reparto del dividendo nacional que toman la forma de ingresos monetarios.

La discusión suscitada a partir de esta formulación es de sobras conocida, ${ }^{7}$ como también lo es la introducción en su reflexión de un elemento abstracto imprescindible para analizar y caracterizar los sistemas económicos: la presencia o ausencia de mecanismos de mercado en la economía de una sociedad concreta. Esto es particularmente importante observarlo en el caso del Bajo Imperio romano, porque los siglos inmediatamente anteriores habían conocido el mayor despliegue de intercambios comerciales que dio la antigüedad.

Pero ¿qué es el mercado?, ¿cómo y dónde lo podemos identificar?

El incuestionable protagonismo del mercado en el seno de nuestras modernas sociedades y su influencia en el revuelto panorama de la economía actual no debe confundirnos. La existencia de un poderoso movimiento especulativo de capitales, aunque trascendental en sus repercusiones, es sólo una parte del complejo mecanismo de funcionamiento institucional del mercado; un mercado que en el modelo económico clásico tiende a la perfección:

\begin{abstract}
"The word "market" need not detain us long. In economics it means, not a particular building or locality, but a state of affairs. There is a "market" in a commodity (i.e. a commodity class) when there are a number of buyers and sellers, and when the unit price offered and paid by each is affected by the decisions of all the others. The market is said to be "perfect" when each buyer has full knowledge, and the ability to use it, of what every seller is demanding, and each seller has full knowledge, and the ability to use it, of what every buyer is offering"
\end{abstract}

Pero el mercado perfecto es una entelequia, una declaración funcional que no se adapta a la realidad institucional y ampliamente atomizada de los mecanismos de oferta-demanda y sus implicaciones. Es más adecuado establecer identificaciones de

6 RodBertus $1865,345-346$.

7 Strobel 2004; Morley 2004, cap. 2 y 143-144; y mis propias conclusiones en FerRer 2005 y bibliografía. El largo recorrido del debate no cesa y son constantes las referencias a los distintos puntos de vista que aporta. Véase, por ejemplo, el trabajo de P. Temin (2001), presentado por su autor como una aportación al debate primitivismo/modernismo, donde afirma que "recent evidence indicates that Finley was wrong; ancient Rome had an economic system that was an enormous conglomeration of interdependent markets" (TEMIN 2001, 181). También se discute a Finley en el trabajo de S. VON REDEN (2002), donde revisa su afirmación sobre la integración de los imperios antiguos en una economía política y el empeño de estos imperios en garantizar el suministro monetario.

8 Fraser 1937, 131-132. 
mercados imperfectos que responden a necesidades de economías sectoriales diversas e independientes, o también cuantificar los costes de transacción en el juego de las relaciones institucionales en la historia del intercambio económico, desde la economía local hasta el comercio a larga distancia, siguiendo el modelo neoinstitucional. Para D. C. North las instituciones son limitaciones concebidas como reglas formales y como restricciones convencionalmente construidas necesarias para contribuir al equilibrio del orden y la seguridad en los mercados y en las sociedades. ${ }^{9} \mathrm{El}$ análisis de los costes de transacción en ese juego institucional se aleja así del teórico libre comportamiento del mercado perfecto que, de acuerdo con el modelo económico clásico, sólo sería posible si el valor de esos costes fuese cero.

En esa complejidad podría perderse tanto la noción del método como la finalidad del análisis en el caso de que los diferentes procedimientos de intercambio se consideraran como mecanismos propios del mercado, pues "el mercado no es el único mecanismo de asignación de recursos en una economía". ${ }^{10} \mathrm{Y}$ todo ello sin perder de vista que el mercado y los mercados son realidades distintas. El primero se singulariza por su calificación como institución social, los otros por su carácter físico y múltiple. ${ }^{11}$

El mercado institucional es el mecanismo creador de precios. ${ }^{12}$ Un mecanismo que resulta de la interacción oferta-demanda y que se desenvuelve en el seno de un sistema que llamamos, precisamente por ello, economía de mercado. En este sistema se hace distinción entre mercados de productos y mercados de factores. Los primeros operan en mecanismos de oferta-demanda sobre mercancías que han sido transformadas para adecuarlas a unas necesidades concretas. El carácter finalista de estos productos, más las carencias que provocan su adquisición, permiten calificarlos igualmente como mercados de bienes de consumo. En cuanto a los mercados de factores, estos engloban las transacciones llevadas a cabo en torno a la oferta-demanda de recursos naturales, recursos humanos y dinero. Son los llamados mercados de la tierra, de trabajo y de capital, en los cuales se pueden obtener todos los elementos productivos básicos, sin los cuales la oferta generada en los mercados de bienes de consumo no existiría.

El elemento consustancial y derivado del funcionamiento oferta-demanda en todos estos mecanismos es el precio, que antes de atender al juego del gusto y la necesidad (en lo que respecta a la demanda) debe responder a criterios de mínima rentabilidad en la parte ofertante, es decir, cubrir y superar los costes en los mercados de productos, a los que se añaden consideraciones extraeconómicas en el caso de los mercados de factores. Cuando los economistas analizan comportamientos derivados de estos mercados creadores de precios fluctuantes, entendemos que se refieren al llamado sistema de mercado autorregulado, es decir, un conjunto elevado de mercados sectoriales que se interrelacionan e interactúan cada vez que uno de ellos se ve afectado por condiciones del tipo que éstas sean, y que por su complejidad sólo existe desde el último tercio del siglo XIX.

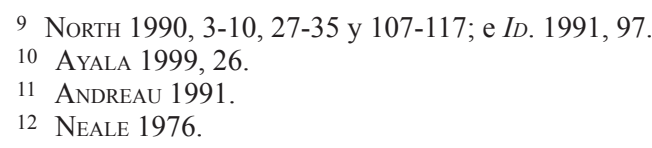


Todos estos conceptos básicos ayudan a distinguir sin dificultad entre ese mercado institucional y los mercados físicos en los que se reúnen las personas para comerciar productos ${ }^{13}$ con la salvedad de que toda acción de intercambio no constituye forzosamente una acción de mercado en el sentido dado por los economistas. Mientras estos analizan dicha acción mercantil como un procedimiento de canje independiente de su entorno social, el análisis de los intercambios de mercado en la Antigüedad no puede prescindir de los elementos culturales que los envuelven. ${ }^{14}$

El mercado creador de precios ha sido una excepción histórica, pues los seres humanos han convivido más habitualmente con las relaciones de carácter económico basadas en la reciprocidad, la redistribución y los precios fijados de antemano, tanto en el comercio por tratado o comercio administrado, como en el comercio de mercado, según la terminología que defienden los sustantivistas, ${ }^{15}$ para quienes el mercado institucional no surge antes del siglo IV a.C., aunque ello no implica la desaparición de los otros procedimientos de transacción, con los que convive en el seno de una misma sociedad. El comercio regulado, consecuencia del procedimiento redistributivo, se mantiene en aquellas sociedades cuyo Estado "no puede imponer normas de mercado de una forma clara". ${ }^{16}$

\section{EL CASO ROMANO, ¿ECONOMÍA REDISTRIBUTIVA O ECONOMÍA ORGANIZADA?}

A pesar del evidente dinamismo comercial que Roma practicó entre sus extensos dominios, no fue la actividad mercantil el objeto económico de interés prioritario; ese privilegio correspondió a la propiedad de la tierra y sus rentas agrícolas que a finales del imperio superaban en proporción de 20 a 1 las procedentes de la industria artesanal y del comercio. ${ }^{17} \mathrm{La}$ economía romana se caracterizó por una ausencia total del concepto de inversión productiva; los grandes propietarios consumían riquezas por tres principales razones: la derivada de su propia condición de ciudadanos acomodados, el placer de su uso y disfrute, y la ostentación pública de las mismas; pero no invertían formalmente en empresas que pudieran caracterizarlos como grupo social. $\mathrm{Su}$ idea del lucro se materializaba en los conceptos de propiedad y préstamo y no en los de explotación y participación directa. ${ }^{18}$ Otro elemento tradicional de esta economía fue el proceso dinamizador de intercambio provocado por la expansión territorial, el

13 Andreau $(1991,367)$ se refiere a algunos de estos espacios: el mercado permanente al detalle en las plazas centrales de las ciudades; el de los macella romanos; las ferias casi semanales de las nundinae, o las que se celebraban uno o más veces al año, llamadas penegyreis entre los griegos y mercatus para los romanos; y también los puertos fluviales y marítimos. Las características de estos mercados en Roma permitieron su ordenamiento mediante un sistema normativo que SERRAo (2000, 37 ss.) denomina "derecho del mercado". Véase también Morley 2000, sobre la distinción conceptual entre nundinae y "el mercado" en abstracto.

14 Es el caso del agora griega, "firmemente incrustada en la escala de valores de la polis" (VON REDEN 1995, 105).

15 Polanyi 1976, 289 y ss.

16 CHIC 2009, 166-178.

17 JONES 1964, 465.

18 Garnsey - Saller 1991, 62. 
mantenimiento de los ejércitos en campaña y el abastecimiento de Roma: la annona imperial. El transporte de grano en concepto de tributo a la Urbs, ${ }^{19}$ las necesidades del ejército ${ }^{20}$ y los suministros de aceite de oliva bético, ${ }^{21}$ constituyeron obligaciones derivadas de la organización estatal, resueltas incluso mediante obligaciones fiscales de las provincias y por tanto incluidas en el marco de una economía intervencionista. ${ }^{22}$

En este proceso no hubo mecanismo de oferta y demanda y libertad de precios, sólo un procedimiento estatal forzado por las necesidades de gestión pública. Un comercio por orden del emperador y ejercitado bajo su control. En suma, un proceso de redistribución y comercio regulado en coexistencia con operaciones de libre mercado, aunque éstas fueran cuantitativamente menos importantes que las transacciones de gestión estatal. Todo ello beneficiado por el ambiente de condiciones altamente favorables que provocó la aparición del Principado, gracias al cual la economía alcanzó durante el siglo II de nuestra era el punto álgido de su crecimiento. ${ }^{23}$ Esas condiciones incluían un entramado de rutas terrestres perfectamente diseñadas y mantenidas, una red fluvial que facilitaba el movimiento de mercancías con las tierras del interior, y especialmente la utilización del Mediterráneo, sobre el que se volcaba el perímetro demográficamente más denso y con mayores niveles de consumo de todo el Imperio; un mar pacificado, sin piratería y alejado de las zonas terrestres conflictivas, con favorables condiciones de navegación y puertos estratégicos para la carga y la distribución de los productos en un periodo de acelerado crecimiento de la demanda, tanto en consumibles como en productos suntuarios y lujosos.

El comercio fue el principal referente de la nueva economía mercantil, operando en todas las direcciones derivadas del amplio ámbito geográfico del territorio imperial y aplicado en corrientes de tráfico definidas por la naturaleza o por la procedencia de las mercancías, configurando lo que Temin define como "un enorme conglomerado de mercados interdependientes". ${ }^{24}$ En el comercio interior, tanto local, como interregional o centralizado -un comercio esencialmente mediterráneo pero complementado en las costas atlánticas y los territorios continentales-, encontró el Imperio

\footnotetext{
19 Bajo Augusto entre 200.000 a 400.000 toneladas por año (GARNSEY - SALLER 1991, 104-105).

20 Entre 100.000 y 150.000 toneladas anuales de trigo durante los siglos I al III (GARNSEY - SALLER 1991, 109-111).

21 Calculado en 6 litros por persona y año (siglos I-III), para una población de un millón de personas (RemESAL 2004 y 2005).

22 J. Remesal sostiene que el oficio de la annona no sólo atendía las necesidades de la ciudadanía de la Urbs, sino también el abastecimiento del ejército con precios directamente intervenidos: "controlar los precios de mercado en Roma es, en mi opinión, la función principal de la praefectura annonae" (Remesal 1986, 85). En contra de esta postura L. Wierschowski cree que el abastecimiento militar respondió a un inconfundible mecanismo de mercado, generado por las necesidades de los soldados y adquirido libremente por ellos (Wierschowski 2000). Véase la réplica en Remesal 2004. E. Lo Cascio duda del sistema redistributivo que se deriva del modelo de Remesal sobre la exportación de aceite bético al limes germano. Un modelo del que discrepa en base a su propia interpretación de los tituli picti (posición $\beta$ ) de las ánforas Dressel 20 del monte Testaccio (Lo CASCIO 2007).

23 R. SALLeR (2002) ofrece un listado de causas sobre el crecimiento del periodo, entre las cuales la importancia de las instituciones imperiales y el liderazgo económico de Italia "with consistent growht through the Principate, as would be predicted by North's neo-institutionalism".

24 Temin 2001, 181.
} 
la satisfacción de la mayor parte de sus demandas, excepción hecha de los productos exóticos. Pero aunque la bonanza de la época favoreció la innegable dimensión de unas operaciones mercantiles a gran escala, no resulta verosímil que el trueque y el autoabastecimiento desaparecieran en el seno de una sociedad rural, con la inmensa mayoría de la población del Alto Imperio ocupada en actividades agropecuarias y el consecuente predominio de la economía doméstica sobre el intercambio mercantil. ${ }^{25}$

El estudio de los precios del trigo ha llevado a D. Kessler y P. Temin a la conclusión de que en los dos primeros siglos de nuestra era el Imperio romano estuvo plenamente monetizado. Con el absoluto dominio romano del Mediterráneo, la economía altoimperial habría dispuesto de dos estándares monetarios -sestercios en la parte occidental y dracmas en la oriental-con tasa fija de intercambio entre ambos, facilitando con ello las operaciones mercantiles a lo largo y ancho de todas las provincias. El resultado fue un mercado plenamente integrado, con menores costes de transacción en los intercambios de larga distancia, pero sin que ello signifique que el suministro de monedas estuviera al alcance de toda la población. ${ }^{26}$ Para C. Katsari, la monetización del Imperio dependía principalmente de la existencia de centros urbanos y su efecto de atracción sobre los campesinos de la zona, los comerciantes llegados a ella desde otros lugares, y los militares de los campamentos cercanos, en el caso de las tierras fronterizas. ${ }^{27}$

Así pues, hubo coexistencia entre las operaciones de mercado, propias de una economía monetaria, con los procedimientos de intercambio practicados en aquellos lugares donde el uso de la moneda y la aplicación del mecanismo oferta-demandaprecio no fueron efectivos por la ausencia de urbanización o lejanía de los grandes centros de comercio. ${ }^{28}$ Además, las importantes transacciones mercantiles que ocupaban el grueso de la economía romana, no logran enmascarar el rostro de una sociedad preindustrial cuyo sistema de valores predominante pertenecía a la aristocracia terrateniente, arraigada en su modelo económico tradicional de grandes propietarios. Este modelo sólo habría podido modificarse con la evolución de un grupo de ricos comerciantes hacia una nueva mentalidad empresarial, dispuestos a invertir en manufacturas artesanales por el beneficio económico en sí mismo, y la consecuente transformación de antiguos mercados de abastecimiento en centros de consumo con mayor volumen en la demanda. Pero tal disposición empresarial, si hubiese existido, habría hallado grandes dificultades en el contexto político romano, muy concernido por las acciones intervencionistas imperiales, debido al distanciamiento existente entre el beneficio finalista de los emprendedores y sus negocios, y la gran voracidad fiscal del Estado.

\footnotetext{
25 A pesar de reconocer este predominio, P. Temin sostiene que "the economy of the early Roman Empire was primarily a market economy" (TEMIN 2001, 169).

26 KessLer - TEMIN 2008.

27 Katsari 2008. Según McMullen (1970, 333), al menos las tres cuartas partes del valor de los intercambios en época romana tuvo lugar en los mercados de ámbito comarcal.

28 BANG (2006) propone un término medio entre el intercambio "primitivo" y el "moderno" sistema de mercado para adecuarlo mejor al concepto de economía romana, y propone el modelo industrial bazaar basado en los usos mercantiles de los bazares orientales.
} 
Un ejemplo de ello lo tenemos en la tasa de la collatio lustralis, la imposición fiscal instaurada por Constantino para ser recaudada entre todos los comerciantes de bienes y servicios, que fue una auténtica pesadilla para los contribuyentes obligados a soportarla. Inicialmente recaudada en oro y en plata -y por ello también llamada crisárgiro- acabaría siendo pagada exclusivamente en oro durante el siglo $\mathrm{V}^{29} \mathrm{Se}$ aplicaba cada cuatro años y existía la posibilidad de demorar su pago en los cuatro siguientes, de modo que era frecuente llegar al vencimiento con un elevado índice de mora en su recaudación. Así se justifica la dolorosa lamentación que se desprende de este párrafo de Zósimo al describir unos hechos acaecidos en torno al año 314 d.C., en el que más allá de su posible exageración, nos permite entender la situación a la que se veían expuestos los contribuyentes por esta durísima carga tributaria:

"Una vez que llevó a cabo todas estas cosas siguió Constantino derrochando los impuestos en obsequios que no estaban justificados, sino que se dirigían a gentes inmerecedoras de ellos e inútiles, con lo cual resultaba gravoso a los contribuyentes y enriquecía a hombres incapaces de prestar servicio alguno. Pues para él la prodigalidad era motivo de honra. Fue él, asimismo, quien impuso el pago de oro y plata a todos cuantos se ocupaban del comercio en cualquier lugar de la tierra y presentaban a la venta en las ciudades todo tipo de objetos, y lo hizo hasta con los más humildes, sin permitir siquiera que las desdichadas prostitutas se libraran de este impuesto; de modo que cuando se aproximaba el vencimiento del plazo de cuatro años a cuyo término había que aportar este impuesto, podían verse por todas las ciudades duelos y lamentos y, cuando se cumplía el plazo, azotes y torturas aplicados a los cuerpos de quienes a causa de su extrema pobreza no podían sobrellevar una multa. Las madres llegaron a vender a sus hijos, y los padres a conducir a sus hijas al prostíbulo, compelidos a valerse del trabajo de éstas para aportar dinero a los recaudadores del crisárgiro"..$^{30}$

Según podemos comprobar en el Código Teodosiano, también se exigía esta tasa lustral a:

"quienes habiten en el palacio, clérigos, hombres poderosos si practican la compra y la venta, pues ni siquiera los más potentes deben quedar exentos, ya que ellos no deben dedicarse al comercio, o deben pagar la tasa" ${ }^{31}$

Pero no sólo fueron intervencionistas las disposiciones imperiales. También lo fueron las adoptadas por los gobernadores provinciales, como ésta de Pisidia, envuelta en un tono moralizante:

"Puesto que se me asegura que antes de los pertinaces rigores de este invierno, el precio del modius de trigo [8,7 litros o $6,8 \mathrm{~kg}]$ era de 8 o 9 ases, y porque sería pro-

29 De donde recibiría el nombre de aurum negotiatorum (CARLÁ - MARCONE 2011, 241-242).

30 Zósimo, 2, 38, 1-4; traducción de J. M ${ }^{\mathrm{a}}$ Candau Morón, ed. Gredos.

31 CTh. XIII, 1.5. 
fundamente injusto que el hambre de sus conciudadanos se convirtiese en lucro para nadie, prohíbo que se venda trigo a más de un denario el modio" 32

No se puede hablar de mercado libre en estas condiciones de precios intervenidos. $Y$ teniendo en cuenta que el mercado requiere un tipo determinado de individuos implicados en el esfuerzo productivo y equiparados socialmente a cualquier terrateniente, ninguna clase empresarial podría surgir en una sociedad que idealiza al rentista y exprime fiscalmente el trato comercial.

Dicho de otro modo, en el imperio romano no se daban las condiciones favorables para la existencia de un sistema de mercado con carácter exclusivo, ni en sus mecanismos ni en sus protagonistas. ${ }^{33}$ La figura del emperador fue tomada como modelo ideal de aristócrata y rico propietario, y su inapelable capacidad de decisión generó un permanente intervencionismo en todos los asuntos económicos. ${ }^{34}$ Un intervencionismo que no debe interpretarse cual un enfrentamiento entre intereses estatales y privados como si fueran dos cuerpos institucionales. Es cierto que el emperador, como teórico defensor de los intereses públicos, representa al Estado y lleva consigo toda la carga jurídica de los derechos del ciudadano, pero frente a él no existe un cuerpo social de hombres de negocios preocupados por la producción y sus beneficios y conscientes de su fuerza colectiva; en ese lugar sólo encontramos intereses especulativos dispersos y un excesivo afán de lucro entre los traficantes, mientras los terratenientes tienden a identificarse con la postura del emperador. Como destacó Max Weber, se nota en esta época la ausencia de la fuerza colectiva de los posteriores gremios medievales, especialmente los arti maggiori, de los que formaban parte "las gentes cultas y acaudaladas, en el sentido de la burguesía moderna". ${ }^{35}$

En el preámbulo del Edicto del precio máximo, promulgado en el año 301, Diocleciano (qui parentes sumus generis humani) se proclama ostentosamente defensor de la "utilidad pública" y de los "intereses comunes", y arremete contra los comerciantes de productos de primera necesidad, a los que califica como verdaderos delincuentes.

Conviene recordar que en algunas ocasiones coincidían en el mismo estatus el terrateniente y el mercader, confirmando una vez más la indefinición socioeconómica de los notables y la ausencia de la fuerza corporativa del gremio. En estos casos, la prohibición imperial de vender a precios desorbitados castigaba doblemente la especulación sobre el productor que traficaba en bienes de consumo, y con ello provocaba el enfrentamiento con los ricos propietarios. Un buen ejemplo de este escenario nos lo proporciona el emperador Juliano al instalarse con su ejército en Antioquía en los

\footnotetext{
32 MC CRUM - WoOdHEAD 1961, n. 464. Eso significa que se vendía a precios desorbitados, pues 1 denario $=16$ ases.

33 ANDREAU (1994) enfatiza la finalidad política o social de las intervenciones comerciales favorecidas o promovidas por el Estado. Unas intervenciones cuya finalidad venía dada en función de las preocupaciones y obligaciones de gobierno de los poderes públicos y no por objetivos comerciales.

34 E. Lo Cascio (2003 y 2006) no simpatiza con los conceptos de "redistribución" o "comercio administrado". En su opinión las decisiones de las autoridades imperiales se corresponden con un escenario de mercado, e interpreta las intervenciones del emperador como acciones propias de una persona privada dentro de las condiciones del mercado, sobre el que influye sin suprimirlo (Lo CASCIO 2006, 225).

35 Weber 1964, 276.
} 
años 362-363 en su campaña contra los persas. En febrero del año 363, cuatro meses antes de su muerte en el campo de batalla, Juliano dejó escrito su "Discurso de Antioquía" o Misopogon, un alegato contra los habitantes de esta ciudad, bastión del cristianismo, en respuesta a la antipatía y poco aprecio con que le habían recibido. ${ }^{36}$ En tono irónico y autocrítico, el emperador mantiene en el discurso su personalidad y sus decisiones, y de su escrito nos interesan especialmente los comentarios acerca de las medidas que tomó contra todos aquellos notables de la ciudad que a su parecer acentuaban la carestía de bienes necesarios, en un momento de grave crisis económica causada por una pertinaz sequía:

"Tú [se refiere a sí mismo] te has ganado la enemistad de los comerciantes al impedirles vender sus mercancías al precio que quieran a los habitantes y a los transeúntes. Y los comerciantes acusan a los propietarios de la tierra. Y tú [de nuevo se refiere a Juliano] también has convertido a éstos en enemigos tuyos al obligarles a actuar con justicia. Los curiales de la ciudad sufren una doble pena, pues así como, en mi opinión, antes se alegraban de recolectar ingresos dobles como propietarios y como comerciantes, ahora, como es natural, se quejan de verse privados de este doble beneficio" ${ }^{37}$

Y casi a continuación sentencia: "a los ricos les prohíbo que lo vendan todo a precio de oro". 38

La antipatía de los negociantes antioquenos había nacido con la restricción aplicada a los precios de venta, de ahí la respuesta del emperador. Pero las quejas de comerciantes y vendedores minoristas se basaban en la dificultad de soportar las pérdidas que les provocaba el edicto imperial, pues la presencia del ejército en la ciudad había agravado la necesidad de bienes y el aumento de los precios. ${ }^{39}$

En general, estas disposiciones carecían del rigor necesario para abordar y solucionar el problema más allá de la simple regulación temporal de precios, pero en este caso, al advertir el emperador que la crisis principal era consecuencia de la carestía de grano, tomó la decisión de importar trigo y venderlo en mejores condiciones:

"El pueblo, en el teatro, presionado por los ricos comenzó a gritar: “¡Tenemos de todo, pero todo está muy caro!" Al día siguiente tuve una reunión con vuestros notables y traté de convencerles de que era mejor que dejaran a un lado las ganancias injustas y obrasen correctamente con sus conciudadanos y con los extranjeros. Y aunque ellos me prometieron que se ocuparían del asunto, al despreocuparme yo y esperar durante los tres meses siguientes, se mostraron tan indiferentes al caso como nadie hubiera podido esperar. Cuando vi que lo que el pueblo gritaba era cierto, y que el mercado estaba en dificultades, no por falta de mercancías, sino por el deseo insaciable de los propietarios, ordené un precio justo de cada producto e hice que la orden fuese conocida por todos. Como de todo lo demás había en abundancia, pues había vino, aceite y todo lo demás, y en cambio existía penuria de trigo por la tremenda esterilidad producida por las sequías anteriores, decidí enviar por él a Calcis, Hierápolis y otras ciudades de los alrededores, de donde os traje 400.000 medidas. Y cuando se gastó esta cantidad, gasté

36 Downey 1951.

37 Juliano, Discursos, 12, 20; la traducción de los Discursos es de J. García Blanco, ed. Gredos.

38 Juliano, Discursos, 12, 28.

39 Sócrates, Historia Eclesiástica, 3, 17. 
primero 5.000, luego 7.000, y ahora otros 10.000 modios, como se les llama ahora nacionalmente, todo ello a mis expensas. El trigo que me trajeron de Egipto se lo di a la ciudad y en vez de exigir el precio fijado por 10 medidas, he cedido 15 al precio que antes se pedía por 10 " 40

La llegada de trigo desde otras zonas con excedentes demuestra el carácter perversamente especulativo de la crisis, y también la escasa capacidad de los comerciantes antioquenos para importar grano y competir con quienes forzaban la compra de existencias a precios desorbitados. Aunque es posible que se lo impidieran los grandes productores, convertidos en meros acaparadores del escaso trigo local, y poco dispuestos a permitir el libre funcionamiento del sistema de mercado. En ese caso, sólo el poder y la determinación imperial lograron resolver, al menos momentáneamente, la grave situación.

El mismo afán especulativo subyace en el relato de Libanio sobre su intervención en la nueva crisis que se cernió sobre Antioquía algunos años después de la solución de Juliano. Entre 381 y 383, la sequía y el hambre originaron graves disturbios ciudadanos a los que Libanio se enfrentó utilizando su experta retórica, salvaguardando a los panaderos de las iras populares. ${ }^{41}$ En 384, las medidas de las autoridades aumentaron las pérdidas económicas de estos artesanos, y sólo la intervención de Libanio devolvió el pan a las tahonas. ${ }^{42}$ Esta rapidez en la solución sugiere que hubo un previo acaparamiento especulativo.

El proceso de aumento de la demanda, escasez de oferta e inflación, y la consecuente intervención de las autoridades, demuestra hasta qué punto convivieron el sistema de mercado y el procedimiento de redistribución. Los productos básicos y necesarios que, por medio de los mercados físicos semanales de ámbito local (nundinae), abastecían todo el Imperio, suavizaron las dificultades provocadas por el retraimiento del comercio internacional de bienes de consumo durante el siglo III. El mecanismo de mercado no podía operar en los casos en los que la necesidad se veía exacerbada por una carestía provocada por la codiciosa especulación, aunque habrá quien opine que la especulación en sí misma se justifica por la "mano invisible" del mercado.

\section{LA ECONOMÍA EN CRISIS}

A pesar de ciertas dificultades concretas, como las anteriormente expuestas, durante el siglo IV se evidencia una reanimación general del comercio, especialmente en las provincias orientales que fueron quienes soportaron mejor el envite de los problemas del siglo anterior y se vieron beneficiadas por la estabilidad y la paz del nuevo periodo. El mercado, integrado y favorecido por un sistema monetario común que había caracterizado la época altoimperial, ${ }^{43}$ comenzó a fragmentarse durante el siglo

40 Juliano, Discursos, 12, 41.

41 Libanio, Discurso I, 205-208.

42 Discurso I, 226. Petit 1955, 119-121.

43 Kessler - Temin 2008. 
III, prolongando su regionalización y los distintos niveles de producción y comercio entre los territorios que formaban parte del Imperio romano, hasta alcanzar los profundos y trascendentales cambios del siglo VII. ${ }^{44}$

Pero en este nuevo periodo, el protagonismo del emperador no disminuyó. Así lo demuestran las medidas adoptadas por Constantino. La economía se resintió por la falta de confianza en la moneda de vellón, cuyo uso había sido potenciado por Diocleciano, y la reacción de Constantino fue la de poner en circulación una nueva moneda, el solidus de 4,54 gramos y una ratio de 72 monedas por libra de oro, una moneda fuerte en su valoración y notablemente apreciada por el precioso metal en el que fue acuñada. Esta nueva moneda permitió soportar las más importantes negociaciones de intercambio hasta bien entrado el siglo $\mathrm{V}$, pero eliminó el numerario de bronce hasta el extremo de tener que utilizar el oro para pagos en transacciones cotidianas. Como reconoce el anónimo autor del De rebus bellicis, ${ }^{45}$ la excesiva circulación de oro perjudicó gravemente a las clases inferiores, y agrandó las diferencias entre ricos y pobres al perderse toda credibilidad y confianza en las monedas de bronce que venían siendo usadas cotidianamente por éstos últimos. ${ }^{46}$

La importancia de la redistribución y el comercio regulado superaron con mucho la presencia institucional del mercado y su mecanismo autónomo de creación de precios, los cuales debieron más a las decisiones de los gobernantes que al impulso de la oferta y la demanda. Efectivamente, la formación de precios en el Bajo Imperio no sólo obedeció a criterios de oferta-demanda, de intermediación comercial y de cercanía o alejamiento a los centros productores con los consiguientes costes de transacción; también la cantidad de metales en circulación tuvo una gran influencia en el proceso. Durante el siglo III las manipulaciones en el numerario de plata habían lastrado la actividad mercantil: el antoniniano, creado por Caracalla en 215, con una equivalencia de dos denarios pero rebajado en un $20 \%$ el contenido en plata, fue perdiendo continuamente la proporción de metal, convirtiéndose en una despreciable moneda de vellón hasta que Aureliano, en 274, fijó su acuñación en la proporción de una parte de plata por veinte de cobre. ${ }^{47}$ La percepción de los impuestos estatales en moneda se había visto resentida por los graves problemas financieros surgidos desde finales del siglo II, y su repercusión inflacionaria sobre los precios forzó el cambio hacia una tasación en especie a partir de Aureliano. La recaudación en moneda no desapareció, pero se perdió su uso como medida de valor. ${ }^{48}$

Diocleciano intentó restaurar con su edicto el poder adquisitivo del oro a los niveles anteriores al 274. Más allá del éxito que sus medidas pudieron tener a corto plazo, lo cierto es que el oro alcanzó a finales del siglo IV un aumento dos veces y media superior al nivel anterior a 274, en el que se mantuvo durante los dos siglos siguientes. ${ }^{49}$ Fue en estos siglos IV y V cuando la emisión de oro, o si se prefiere su

44 McCormick 2001, 83-119.

45 De rebus bellicis II, 1.

46 BANAJI 2001, 39-88.

47 El protagonismo de este emperador en la reforma justifica que algunos autores modernos denominen aureliniano a la nueva moneda (CALLU 1969, 325-327).

48 Lo CASCIO 1997.

49 Rathbone 2009, 317-321. 
cantidad y calidad, causó en buena medida el alza de los precios. La fase más alcista se dio durante el periodo 300-367, en el que la cotización del oro y la plata creció un 16,90 y $17,46 \%$ anual, respectivamente,,$^{50}$ mientras algunos productos comunes como el trigo, ciertas carnes y pescados, el vino, las aceitunas, el aceite y algunos animales sufrieron alzas similares en sus precios (entre el 16 y el 20\% anual). En las dos décadas siguientes se estabilizaron algunos precios - como el del trigo- y otros moderaron su crecimiento por debajo del 3\%. A partir del año 390, en vez de fijar el valor de los productos por precio unitario y nominal, se impuso la costumbre de establecer una relación entre un número de objetos y el peso en oro. Ciertos precios descendieron ligeramente y otros se estabilizaron o siguieron un alza moderada en torno al 3\% hasta finales del siglo $\mathrm{V},{ }^{51}$ colaborando con ello en el proceso de reactivación económica generado durante ese último siglo.

El estudio actual de la economía bajoimperial se halla muy concernido por la imagen decadente y regresiva que ha venido proyectando el siglo III sobre todos los acontecimientos posteriores; una visión negativa y exagerada que ha provocado discusiones acerca de un hipotético regreso a la economía natural, en detrimento de la que había sido boyante economía monetaria altoimperial. ${ }^{52}$ La desaparición de la moneda en un gran número de transacciones fue el resultado de la espiral inflacionista y el aumento progresivo del precio de los metales nobles, pero en el descenso de las relaciones a larga distancia y en el proceso de regresión comercial fueron transcendentes la inestabilidad política, las luchas por el poder, la permeabilidad fronteriza y la amenaza permanente de los pueblos bárbaros. Sin embargo, las necesidades de una población habituada al intercambio no desaparecieron, las operaciones de abastecimiento de un complejo ejército vigilante en los márgenes del Imperio incluso aumentaron, y los excedentes de las zonas más productivas siguieron comercializándose, como demuestra la relación de tarifas de transporte (naula) fijadas en el Edicto del precio máximo.

El siglo IV no fue una época económicamente decadente. Los trabajos arqueológicos sobre el mundo rural en la época tardía disponen de una abundante documentación material, y sus conclusiones ofrecen un panorama de equilibrada bonanza productiva. ${ }^{53}$ La crisis iniciada a finales del siglo II había convulsionado los anteriores tiempos de prosperidad, pero la sociedad romana supo adaptarse a los radicales cambios operados, superando el desgobierno, y facilitando con ello que las instituciones reformadas prolongaran la cohesión del Imperio y mantuvieran el funcionamiento del Estado, aunque al final de la catarsis esa sociedad presentara una fractura aún mayor entre los poderosos y los débiles, entre los ricos y los menesterosos.

\footnotetext{
50 Entre 310 y 370 el precio del oro se incrementó unas 12.000 veces, generando la inevitable la caída del poder adquisitivo de la moneda divisional y el acelerado proceso de inflación generalizada (CARLÀ 2009, tabla 1 y gráficos 1 a 3 ).

51 Depeyrot 1996, 127-136. Véanse las tablas sobre precios del grano y del trigo en unidades de cuenta y en oro en Lo CASCIO 1997, 174-177.

52 BANAJI 2001, 23-38, aporta datos para ese debate, y apoyándose en la obra de Mickwitz acerca de la vitalidad monetaria del siglo IV, rechaza las ideas de Weber sobre el aislacionismo de la antigüedad tardía.

53 "El siglo IV es, en lo que al mundo rural se refiere, un siglo de oro, un periodo de esplendor y estabilidad productiva" (ARIÑo - DíAz 2002, 59).
} 
Gran parte de esa adaptación se debe a la tregua de los pueblos bárbaros en sus ataques y el reforzamiento de las líneas fronterizas de defensa. Sin descuidar la atención militar y la vigilancia permanente, los gobernantes pudieron acometer diversas reformas, e incluso sostener luchas internas por el poder. La relativa tranquilidad en las provincias interiores repercutió en una cierta recuperación de la vitalidad ciudadana y de las actividades productivas, en un panorama socioeconómico modificado en gran parte a causa de la elevada presión fiscal. Las imposiciones contributivas de las comunidades, previamente calculadas y exigidas por los funcionarios estatales, debían ser recaudadas por los curiales bajo el principio de corresponsabilidad pecuniaria. Esta obligación les conminaba a extraer de los ciudadanos más débiles las cargas impositivas eludidas por los más poderosos, lo que a su vez les convertía en individuos temidos y odiados entre los contribuyentes. La situación se agravaba porque los grandes propietarios no sólo evitaban tales exacciones, sino que hacían otro tanto con sus posibles nombramientos como curiales al fijar sus residencias permanentes en las villae, convertidas ahora en centros autosuficientes, desligados de la economía y el control ciudadanos. ${ }^{54}$ Pero esta autonomía no afectó a los intereses comerciales. La ciudad y el campo continuaron su estrecha relación, ahora adecuada a la realidad de estas villae, constituidas como nuevos centros de consumo. El flujo de intercambio fue recíproco: mientras en algunas disposiciones legales se vislumbra una relación relativamente fluida entre colonos convertidos en eventuales comerciantes que realizan sus intercambios en las ciudades, ${ }^{55}$ también durante el siglo IV se produjo el mayor abastecimiento de productos urbanos a las villae de Hispania, ${ }^{56}$ y el más fluido aporte de monedas como nunca antes había ocurrido. ${ }^{57}$ Es posible que en ello influyera la adaeratio, esa pretensión imperial de percibir los impuestos en oro con preferencia a los tributos en especie. ${ }^{58}$

54 La legislación trataba de impedir esta circunstancia habida cuenta de la importancia que tenía para el emperador la administración ciudadana y la recaudación fiscal. Arcadio y Honorio, mediante una medida de escasa aplicación práctica, ordenaron en el año 396 que los curiales no abandonaran las ciudades para vivir en sus propiedades rurales, bajo amenaza de incorporar éstas al fisco y verse privados de ellas: curiales omnes iubemus interminatione moneri, ne civitates fugiant aut deserant rus habitandi causa, fundum, quem civitati praetulerint, scientes fisco esse sociandum eoque rure esse carituros, cuius causa impios se vitando patriam demonstrarint (CTh. 12.18.2).

55 Colonos rei privatae vel ceteros rusticanos pro speciebus, quae in eorum agris gigni solent, inquietari non oportet. Eos etiam, qui manu victum rimantur aut tolerant, figulos videlicet aut fabros, alienos esse a praestationis eius molestia decernimus, ut hi tantum, qui pro mercimonio et substantia mercis ex rusticana plebe inter negotiatores sunt, sortem negotiationis agnoscant, quos in exercendis agris ingenitum iam pridem studium non retinet, sed mercandis distrahendisque rebus institutum vitae et voluntatis implicuit (CTh. 13.1.10).

56 El nuevo empuje de la edificación y costoso embellecimiento de las villae en Hispania durante este periodo (CHAVARría 2005), sólo se justifica mediante el incremento de la riqueza derivado de los excedentes productivos.

57 ARIÑO - DíAZ 1999.

58 Según el modelo propuesto por Hopkins (1980, 1995-1996), la intención de Constantino y sus sucesores fue la de activar la circulación monetaria mediante la inyección en el sistema de intercambio de una gran cantidad de metales nobles extraídos de las reservas del Estado y la incautación de las riquezas de los templos, de tal modo que el oro y la plata circulante actuaran a su vez como estímulo de los capitales particulares, y la masa monetaria, aumentada, retornase a las arcas imperiales por vía tributaria como ya había ocurrido en el Principado ante la necesidad de pagar los impuestos en moneda por exigencia de Augusto. Este modelo ha 
La resiliencia del mundo rural durante la Antigüedad Tardía ha sido resaltada por Banaji, quien ha estudiado a fondo el periodo y ha extraído de las fuentes consultadas un panorama de asentamientos en todo el Imperio que van desde las ricas villae hasta las más modestas instalaciones agrarias, como los castella, vici y casae en la zona central y occidental del Mediterráneo ${ }^{59} \mathrm{y}$ comunidades más densamente pobladas en la oriental, rodeadas de tierras más fértiles y productivas. El campo tardorromano recibió fuertes inversiones procedentes de las acumulaciones de oro surgidas tras la política monetaria de Constantino y sus sucesores, y la ampliación de las tierras de cultivo repercutió en una mayor producción y en el comercio de los excedentes. La prosperidad del agro tardorromano tuvo mayor incidencia en las provincias orientales, donde incluso se reocuparon zonas rurales abandonadas durante el Alto Imperio, como en Grecia, o se ampliaron tierras de labor en lugares marginales como las colinas orientales de Antioquía o territorios del desierto sur y occidental de Nessana, mientras en Egipto, donde las posibilidades de ampliación de tierras se hallaba muy limitada, la inversión de los ricos propietarios se orientó hacia la producción agrícola basada en campos permanentemente irrigados. ${ }^{60}$

Por tanto, el protagonismo de la economía agropecuaria en época tardía no es fruto de la ausencia de mecanismos de mercado y la merma de intercambio comercial. Es un protagonismo tradicional, permanente, basado en actividades y ocupaciones sólidamente arraigadas en las sociedades antiguas y en la cultura romana en particular. La autosuficiencia absoluta en tiempos de profundas transformaciones es poco probable en la mayor parte de unidades productivas, e incluso en ese caso no resultaría fácil prescindir de productos de manufactura que habían formado parte de privilegiados ajuares domésticos hasta esa época. Al margen de las grandes construcciones residenciales que los presidían, la diferencia sustancial entre los centros de producción del Bajo Imperio y sus antecesores fue el fenómeno de concentración de la propiedad como consecuencia de matrimonios entre herederos, ejecuciones hipotecarias, arrendamiento de tierras del patrimonium, e incluso por adscripciones de colonos propietarios. Estas grandes posesiones de la tardoantigüedad generaron los excedentes agrícolas necesarios para sostener el abastecimiento imperial y propiciar un flujo de intercambio de mercados interregionales, con operaciones pagadas mediante moneda noble. Pero todo ello carecía de futuro a medio plazo. La ausencia de espíritu mercantil ${ }^{61}$ entre las élites ricas y la enorme grieta socioeconómica que se abría entre éstas y un mísero campesinado, impidió el crecimiento económico. Hubo que esperar hasta finales de la Edad Media y el Renacimiento, para encontrar las condiciones favorables que recuperaran la economía mercantil y a los hombres que la protagonizaran.

\footnotetext{
sido puesto en duda por diversos autores (véase VON REDEN 2002), pero su influencia en la discusión científica es permanente.

59 Pueden identificarse con las llamadas agglomérations secondaires de Galia y Germania, según la terminología utilizada por algunos autores. Véase PetiT - Mangin 1994.

60 BANAJI 2001.

61 A pesar de ser conscientes del bienestar que el comercio aportaba a su vida cotidiana, las élites romanas y sus gobiernos no mostraron una actitud de pleno compromiso en su desarrollo (HARRIS 2003).
} 


\section{CONCLUSIONES}

Fueron aspectos sociales y políticos los que condicionaron el tipo de economía romana. Las autoridades estatales se convirtieron en activos agentes de un mercado intervenido, cuando al proporcionar el necesario abastecimiento a la población y al ejército actuaron sobre los precios y las condiciones de compraventa. Sus decisiones respondieron a obligaciones derivadas del oficio de gobierno y nunca se diseñaron y ejecutaron como medidas de dinamismo o reactivación económica. La globalidad mercantil de los siglos I y II se fue desvaneciendo como consecuencia de la crisis posterior y por la ausencia de una política monetaria de equilibrio y continuidad. El mercado integrado se fue comprimiendo en zonas de comercio regional, mientras se reducía fuertemente el anterior intercambio generalizado y habitual entre los distintos territorios del Imperio. La mayor parte de la población, que se abastecía en mercados locales, se vio gravemente afectada por estos cambios, especialmente cuando el excesivo aporte de numerario de oro acabó con la moneda de bronce. Pero la necesidad alimenticia tuvo que generar una mayor demanda de productos en los mercados locales, y el descenso de importaciones debió ser suplido por excedentes cercanos.

El proceso de adquisición, ampliación, adecuación y acumulación de tierras de cultivo alcanzado en el siglo IV engendró grandes fortunas y procuró generosos beneficios para los propietarios, al tiempo que aumentaba el enorme distanciamiento social y económico con el campesinado. Las inversiones necesarias para las nuevas explotaciones agrícolas, las edificaciones de las residencias señoriales y la decoración de estas villae, son manifestaciones de un tiempo de bonanza y poder para estas selectas élites, y demuestran el valor de los excedentes y su necesaria comercialización para conseguir las riquezas con las que embellecer sus posesiones. También la proliferación de pequeñas agrupaciones rurales en esta época demuestra la importancia económica de la producción agrícola; y el protagonismo del campo y su atracción se evidencia en las disposiciones imperiales que intentan, con escaso éxito, retener a los personajes principales en las ciudades. Pero hay que reconocer que el peso sustancial de la actividad agraria y su beneficio en la economía romana, acomodó todavía más a los grandes propietarios, quienes resultaron incapaces de ver más allá de los resultados agrícolas y fueron torpes para emprender nuevas actividades y negocios mercantiles con el producto de sus excedentes. Los tiempos de crisis, que tan útiles pueden resultar para llevar a cabo sustanciales cambios y progresos, quedaron en esta ocasión convertidos en una oportunidad perdida.

Al menos quedó la tradicional seguridad del campo. Y así, cuando las crisis en la gobernanza o los desajustes de producción y abastecimiento afectaron gravemente a ciertas comunidades, o distorsionaron el mantenimiento del ejército imperial, la básica economía agropecuaria siguió proporcionando los medios propios de subsistencia y los excedentes productivos, independientemente de que unos y otros fuesen adquiridos por trueque, redistribuidos u ofertados al mercado, en el seno de una economía que, por ello, podemos llamar plural. 


\section{BIBLIOGRAFÍA}

AndreAU, J.

(1991): "Mercati e mercato", [en] G. Clemente - F. Coarelli - E. Gabba (eds.), Storia di Roma II: L’impero mediterraneo. 2. I principi e il mondo, Turín, 367-385 (= J. Andreau, Patrimoines, échanges et prêts d'argent: l'économie romaine, Roma, 1997, 311-334).

(1994) : “La cité romaine dans ses rapports à l'échange et au monde de l'échange", [en] J. Andreau - P. Briant - R. Descat (dirs.), Les Echanges dans l'Antiquité: le rôle de l'État, Saint Bertrand-de-Comminges, 83-98 (=J. Andreau, Patrimoines, echánges et prêts d'argent: l'économie romaine, Roma, 1997, 385-407).

ARIÑo, E. - DíAz, P.C.

(1999): "La economía agraria de la Hispania romana: colonización y territorio", Studia Historica. Historia Antigua 17, 153-192.

(2002): "El campo: propiedad y explotación de la tierra", [en] R. Teja (ed.), La Hispania del siglo IV. Administración, economía, sociedad, cristianización, Bari, 59-96.

Ayala, J. (1999): Instituciones y Economía. Una introducción al neoinstitucionalismo económico, México.

Banasi, J. (2001): Agrarian change in Late Antiquity, Oxford.

BANG, P. F. (2006): "Imperial Bazaar: towards a comparative understanding of markets in the Roman Empire", [en] P. F. Bang - M. Ikeguchi - H. G. Ziche (eds.), Ancient economies, modern methodologies. Archaeology, comparative history, models and institutions, Bari, 51-88.

Bowman, A. (2009): “Quantifying Egyptian Agriculture”, [en] A. Bowman - A. Wilson (eds.), Quantifying the Roman Economy. Methods and Problems, Oxford.

CAllu, J. P. (1969): La politique monétaire des empereurs romains du 238 à 311, París.

CARLÀ, F. (2009): L'oro nella tarda antichità: aspetti economici e sociali, Turín.

CArlà, F. - Marcone, A. (2011): Economia e finanza a Roma, Bolonia.

Chavarría, A. (2005): "Villas in Hispania during the fourth an fith centuries", [en] K. Bowes - M. Kulikowski (eds.), Hispania in Late Antiquity, Leiden-Boston, 519-552.

CHIC, G. (2009): El comercio y el Mediterráneo en la Antigüedad, Madrid.

Depeyrot, G. (1996): Crisis e inflación entre la Antigüedad y la Edad Media, Barcelona (París, 1991)

Downey, G. (1951): "The Economic Crisis at Antioch under Julian the Apostate", [en] P. R. Coleman-Norton (ed.), Studies in Roman Economic and Social History, Princeton, 312- 21.

Ferrer Maestro, J. J. (2005), "El debate sobre la aplicación de la teoría económica en la Antigüedad: de Johann Karl Rodbertus a Moses I. Finley. Desarrollo historiográfico y estado actual", Revista de Historiografía 3.II, 162-173.

FinKelstein, J.J. (1972): Late Old Babylonian documents and Letters, New Haven.

Fraser, L. M. (1937): Economic Thought and Language: a critique of some fundamental economic concepts, Londres.

Garelli, P. (1963): Les Assyriens en Cappadoce, París.

GARnSEy, P. - SAlLER, R. (1991): El Imperio romano. Economía, sociedad y cultura, Barcelona (Londres, 1987). 
Harris, W.V. (2003): “Roman Governments and Commerce, 300 BC-AD 300”, [en] C. Zaccagnini (ed.), Mercanti e política nel mondo antico, Roma, 275-305 (=W. V. Harris, Rome's Imperial Economy, Oxford, 2011, 198-219).

HopkIns, K.

(1980): “Taxes and Trade in the Roman Empire, 200 BC-AD 400”, JRS 70, 101-125.

(1995-1996) "Rome, Taxes, Rents and Trade", Kodai: Journal of Ancient History VI-VII, 41-75 (=reimp. [en] W. Scheidel - S. von Reden (eds.), The Ancient Economy, Edimburgo, 2002, 190-230).

Jones, A. H. M. (1964): The Later Roman Empire, Oxford, 1964.

Katsari, C. (2008): "The Monetization of the Roman Frontier Provinces", [en] W. V. Harris (ed.), The Monetary Systems of the Greeks and Romans, Oxford, 242-266.

Kessler, D. - Temin, P. (2008): "Money and Prices in the Early Roman Empire", [en] W. V. Harris (ed.), The Monetary Systems of the Greeks and Romans, Oxford, 137-159.

Lo CASCiO, E.

(1997): "Prezzi in oro e prezzi in unità di conto tra il III e il IV sec. d.C.", [en] J. Andreau - P. Briant - R. Descat (eds.), Économie antique. Prix et formation des prix dans les économies antiques, St. Bertrand de Comminges, 161-182.

(2003): "Mercato libero e 'commercio amministrato' in età tardoantica", [en] C. Zaccagnini (ed.), Mercanti e política nel mondo antico, Bari-Roma, 307-325 (=E. Lo Cascio, Crescita e declino. Studi di storia dell'economia romana, Roma, 2009, 273-285).

(2006): "The role of the state in the Roman economy: making use of the new institutional economics", [en] P. F. Bang - M. Ikeguchi - H. G. Ziche (eds.), Ancient economies, modern methodologies. Archaeology, comparative history, models and institutions, Bari, 215-234.

(2007): “L'approvvigionamento dell'esercito romano: Mercato libero o 'commercio amministrato"?", [en] L. de Blois - E. Lo Cascio (eds.), The Impact of the Roman Army (200 $B C$ - AD 476): economic, social, political, religious and cultural aspects, Leiden, 195-206.

McCormick, M. (2001): Origins of the European Economy. Communications and Commerce, A.D. 300-900, Cambridge.

McCrum, M. - Woodhead, A. G. (1961): Select documents of the principates of the Flavian emperors including the year of revolution: AD 68-96, Cambridge.

McMullen, R. (1970): "Market-days in the Roman Empire", Phoenix XXIV, 4, 333-341.

Michel, C. (2001): Correspondance des marchands de Kaniš au début du IIe millénaire av. J.-C. (=Littératures du Proche-Orient ancien 19), París.

Michel, C. - Garelli, P. (1997): Tablettes paléo-assyriennes de Kültepe 1 (Kt 90/k), Estambul.

Morley, N.

(2000): "Markets, Marketing and the Roman élite", [en] E. Lo Cascio (ed.), Mercati permanenti e mercati periodici nel mondo romano, Bari, 211-221.

(2004): Theories, Models and Concepts in Ancient History, Londres-Nueva York.

Neale, W. C. (1976): "El mercado en la teoría y la historia", [en] K. Polanyi - C. M. Arensberg - H. W. Pearson (dirs.), Comercio y mercado en los imperios antiguos, Barcelona, 405-421, (Nueva York, 1957). 
NorTh, D. C.

(1990): Institutions, institutional change and economic performance, Cambridge.

(1991): "Institutions", The Journal of Economic Perspectives 5/1, 97-112.

Petit, P. (1955): Libanius et la vie municipale à Antioche au IV siecle après J.-C., París.

Petit, J. P. - Mangin, M. (DiRs.), BRunella, PH. (COl.) (1994): Les agglomérations secondaires. La Gaule Belgique, les Germanies et l'Occident romain. Actes du colloque de Bliesbruck-Reinheim/Bitche, 21-24 octobre 1992, París.

Polanyi, K. (1976): "La economía como actividad institucionalizada", [en] K. Polanyi - C. M. Arensberg - H. W. Pearson (dirs.), Comercio y mercado en los imperios antiguos, Barcelona, 1976, 289-316, (Nueva York, 1957).

Rathbone, D. (2009): "Earnings and Costs: Living Standards and the Roman Economy (First to Third Centuries AD)", [en] A. Bowman - A. Wilson (eds.), Quantifying the Roman Economy, Oxford, 299-326.

REMESAL, J.

(1986): La annona militaris y la exportación de aceite bético a Germania, Madrid (existe trad. alemana, Stuttgart, 1997).

(2004): "El abastecimiento militar durante el Alto Imperio Romano. Un modo de entender

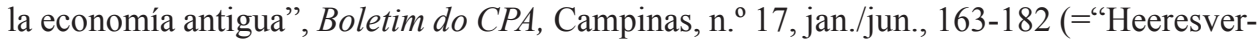
sorgung im frühen Prinzipat. Eine Art, die antike Wirtschaft zu verstehen", Münstersche Beiträge zur Antiken Handelsgesichte 21, 2002, 69-84).

(2005): "Escrito en barro. El monte Testaccio y la Historia Augusta", [en] G. Bonamente M. Mayer (eds.), Historiae Augustae. Colloquium Barcinonense, Bari, 249-256.

Rodbertus, K. (1865): “Zur Geschichte der römischen Tributsteuern seit Augustus, I, Einleitung”, Jarbücher für Nationalökonomie und Statistik IV, 341-427.

Saller, R. (2002): "Framing the Debate over Growth in the Ancient Economy", [en] W. Scheidel - S. von Reden (eds.), The ancient economy: recent approaches, Edimburgo, 251269 (=J. Manning - I. Morris (eds.), The ancient economy: evidence and models, Stanford, 2005, 223-238).

Serrao, F. (2000): “Impresa, mercato, diritto. Riflessioni minime”, [en] E. Lo Cascio (ed.), Mercati permanenti e mercati periodici nel mondo romano, Bari, 31-67.

Strobel, K. (2004): Die Ökonomie des Imperium Romanum: Wirtschaftsgeschichte im Widerstreit zwischen Primitivismus und Modernismus, Poznari.

Temin, P. (2001): “A Market Economy in the Early Roman Empire”, Journal of Roman Studies $91,169-81$.

VON REDEN, S.

(1995): Exchange in Ancient Greece, Londres.

(2002): "Money in the Ancient Economy: A survey of recent research", Klio 84.1, 141-174.

Weber, M. (1964): Historia económica general, México (trad. de la obra póstuma: Wirtschaftsgeschichte, Berlín, 1923).

WierschOWSKI, L. (2001): “Die Römische Heeresversorgung im frühen Prinzipat”, Münstersche Beiträge zur Antiken Handelsgesichte 20, 37-61. 